\title{
On the Possibility of Millimetre-Wave Amplification with an X-Band LSA Oscillator
}

\author{
Majborn, Benny
}

Published in:

1st European Microwave Conference

Link to article, DOI:

10.1109/EUMA.1969.331843

Publication date:

1969

Document Version

Publisher's PDF, also known as Version of record

Link back to DTU Orbit

Citation (APA):

Majborn, B. (1969). On the Possibility of Millimetre-Wave Amplification with an X-Band LSA Oscillator. In 1st European Microwave Conference (pp. 227-230). IEEE. https://doi.org/10.1109/EUMA.1969.331843

\section{General rights}

Copyright and moral rights for the publications made accessible in the public portal are retained by the authors and/or other copyright owners and it is a condition of accessing publications that users recognise and abide by the legal requirements associated with these rights.

- Users may download and print one copy of any publication from the public portal for the purpose of private study or research.

- You may not further distribute the material or use it for any profit-making activity or commercial gain

- You may freely distribute the URL identifying the publication in the public portal

If you believe that this document breaches copyright please contact us providing details, and we will remove access to the work immediately and investigate your claim 
OI! THE POSSIBILITY OF IILLIMETRE-WAVE AMPLIFICATION

WITH AN X-BAND LSA OSCILLATOR

\section{B. Najborn}

Introduction. Theoretical considerations $|I|$ as well as experimental results $|2|$ indicate that, during oscillation, an LSA oscillator viewed as a lunped circuit element exhibits a negative conductance at frequencies from de to approximately $f_{0} / 0$, where $f$ is the LSA oscillation frequency and $\vartheta_{0}$ is the differential of the LoA resonant dircuit, whereas for higher frequencies the conductance is positive.

Iowever, for sicnal frequencies considerably higher than the LSA oscillation frequency, the signal wavelength may be of the same order of magnitude as the lengtin of the LSA oscillator in the direction of signal propagation, so a new analysis is needed taking into account the distributed nature of the oscillator as seen by the signal.

In the small-signal approxination, an LSA oscillator (or a sarple of n-type gallium arsenice externally pumped under limited space-charge accumulation concitions) may be viewed as an anisotropic medium of time-varying conductivity. The conductivity in the direction of the bias field is negative during part of the oscillation period (pump period), and positive during the rest of the period. As a necessary condition for the control of space-charge growth durins a whole pump cycle the average differential conductivity must be positive $|I|$. ijevertheless, an electronagnetic wave, which travels through a pumped gallium arsenide sample with the electric fielo vector parallel to the bias field, may be amplified, if the travelling-length during the part of the purp period when the conductivity is negative is considerably longer than the travelling-leneth during the rest of the period. This condition may be met in LSA operation, where the najor part of the cycle is spent in the region of negative differential conductivity.

A simple one-dimensional analysis of small-signal wave propagation through a pumped Eallium arsenide sample has been carried out. The results to be reported in the following will aemonstrate the possioility of two-port amplification for samples longer than about a quarter of a wave-length at the signal frequency.

iodel. The eeometry considered is schenatically illustrated in fig. la. A. sample of n-type gallium arsenide is assumed to oscillate in the LSA mode (self-oscillating or externally pumped) with the bias field in the y-direction. The pump field is assuned to be uniform across the whole sample and to impart to the sample a time-varying small-signal conductivity in the $\mathrm{y}$ direction.

The injected electromagnetic signal-wave is assumed to travel in the z-direction with the electric field in the $y$-airection. The amplitude of the signal-wave is assumed to be much smaller than the pump anplitude, so that the sample properties nay be derived from the pump field alone.

The problem is assumed to be one-dimensional, i.e. the signal field is assumed to be a function of time and the coordinate $z$ only. The sarnple length in the z-direction is then the only geonetrical parameter.

The pumped sample is simulatea by a transmission-line model with constant distributed series inductance, $L$, and shunt capacitance, $C$, and with time-varying distributed shunt conductance, $G(t)$. The assumed model is sketched in fié. Ib. A segment of the transmission-line represents a small

B. Najborn is with the Laboratory of Iectromagnetic Theory, Technical University of Denmark, Lyngby, Denmark. 
fraction of length $\Delta \mathrm{x}$ of the correspondine sample, so, assuming a unit cross-section area perpendicular to the direction of signal-wave propagation, $I, C$, and $G(t)$ are determined by:

$L=\mu \cdot \Delta x, \quad C=\varepsilon \cdot \Delta x, \quad$ and $G(t)=q \cdot n \cdot d v / d F(t) \cdot \Delta x$,

where $\mu$ is the permeability, $\varepsilon$ is the real part of the permittivity (which is assumed constant), $q$ is the electronic charge, $n$ is the iree carrier concentration (winich is assumed equal to $n_{0}$, the homogeneous concentration of donor atorns) and $d v / \overline{d E}(t)$ is determine ${ }^{\circ}$ from the analytical expression $|3|$.

$v(E)=\left(u_{0} E+v_{s}\left(E / E_{n}\right)^{4} /\left(1+\left(E / E_{n}\right)^{4}\right)\right.$,

where $\mathbb{E}_{\mathrm{n}}=4000 \mathrm{~V} / \mathrm{cm}, \mathrm{v}_{\mathrm{s}}=3.5 \times 10^{6} \mathrm{~cm} / \mathrm{s}, \mathrm{u}_{0}=8000 \mathrm{~cm}^{2} / \mathrm{V} \cdot \mathrm{s}$, and $\mathbb{E}=\mathbb{E}(t)=$ $E_{0}-E_{p o s} \omega_{p} t$ is the purip field.

The transmission-line is assumed to be fed by the source voltage $V_{s} \sin \left(\omega_{s} t+\phi_{s}\right)$, and the boundary conditions for the sample are simulated by the source impedance, $Z_{S}$, and the load impedance, $Z_{\ell} \cdot{ }{ }_{s}$ and $Z_{\ell}$ may be chosen arbitrarily correspondin to various circuit configurations.

From the transmission-line equations and the equations expressing the boundary conditions at the source and at the load, the voltage and current distributions along the transmission-line may then be computed at any time when the initial conditions are specified.

The assumption of a uniform purnp field restricts the maximum sarmple length in the direction of signal-wave propagation to aoout $(1 / 3) \lambda$, where $\lambda_{\text {is }}$ is the wavelength in the sample naterial at the pump frequency $p|4|$. This restriction does not necessarily mean that amplification is not pos-

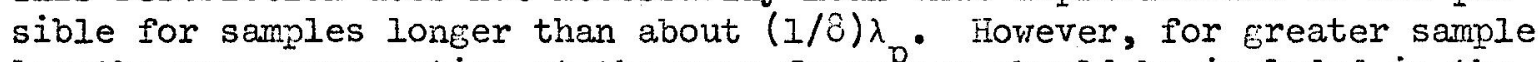
lengths wave-propagation at the purnp frequency should be included in the analysis.

Results. The results to be reported here corresponds to $z_{s}$ and $z_{l}$ both equal to the characteristic imoedance of the lossless transmission-line obtained for $G(t)=0$. A sinusoidal driving voltage is applied to the input of the line for $t \geqslant 0$, with the initial condition that the voltage is zero at all mesh points for $t<0$.

The parameters used in the computations are:

$E_{0}=$ dc bias rield

$\mathbb{E}^{O}=$ LSA oscillation amplitude (pump amplitude)

$n^{p}=$ concentration of donor atons (assumed homogeneous)

$f_{-0}^{\circ}=$ LSA oscillation frequency (pump frequency)

$f_{s}^{2}=$ signal frequency

$\phi_{S}^{s}=$ initial phase of signal voltage

$l^{S}=$ sample length in the direction of signal-wave propagation.

Fig. 2 shows the first three cycles of the computed output waveform

(lower frame). The amplituae 1 corresponds to 0 a gain. The paraneters are given in the figure caption. The upper frame shows the corresponaing electric field across the sample (pump field) and the middle frame shows the corresponaing differential nobility. The waveform is stationary already from the second cycle.

Fig. 3 shows the corresponaing frequency spectrum obtained using the Cooley-Tukey Fourier Transfom $|5|$. The gain at the signal frequency is $0.3 \mathrm{~dB}$, and the sichebands are more than 15 dis below the signal.

Fig. 4 shows the gain at the signal freguency as a function of sarple length for $f_{p}=8 \mathrm{GHz}, f_{s}=64 \mathrm{GHz}, \phi_{s}=0^{\circ}$ and

a) $n / f_{p}=2.5 \times 10^{4} \mathrm{~s} / \mathrm{cr}^{3}$. $E_{0}=7 \mathrm{kV} / \mathrm{cm} \quad i_{p}=4.8 \mathrm{kV} / \mathrm{cm}$

b) $\mathrm{n} / \mathrm{f}_{\mathrm{p}}=5 \times 10^{4} \mathrm{~s} / \mathrm{cm}^{3} \quad E_{0}=10 \mathrm{kV} / \mathrm{cm} \quad \mathrm{I}_{\mathrm{p}}=0 \mathrm{kV} / \mathrm{cm}$ 
c) $\mathrm{n} / \mathrm{f}_{\mathrm{p}}=1 \times 10^{5} \mathrm{~s} / \mathrm{cm}^{3} \quad \mathrm{~T}_{\mathrm{o}}=20 \mathrm{kV} / \mathrm{cm} \quad \mathrm{E}_{\mathrm{o}}=18 \mathrm{kV} / \mathrm{cm}$

The highest gain obtained for these parameters is 1.4 dB for $f_{p}=1 \times 10^{5}$ $\mathrm{s} / \mathrm{cm}^{3}$ and $\ell=(3 / 4) \lambda_{=}=0.993 \mathrm{~mm}$. Because of the choice of solpce and Ioad impedances the matching of the sample becomes poorer and poorer as $G(t)$ is increased. For $\mathrm{n} / \mathrm{f}_{\mathrm{f}}=5 \times 10^{4} \mathrm{~s} / \mathrm{cm}^{3}$ and $f_{s}=64 \mathrm{GHz}$ the maximum value of $\mathrm{G}(t)$ is approximately eqtal to $\omega \mathrm{C}$.

The variation of gain With the phase of the injected signal relative to the phase of the pump field has been computed for $f_{f}=16 \mathrm{GHz}, f_{s}=32$ GHz and $f_{s}=64 \mathrm{GHz}$. The variation is only marked at the lower signal frequencies.' For a sample length of $1.325 \mathrm{~mm}=(1 / 8) \lambda$ and $\mathrm{n} / \mathrm{f}=5 \times 10^{4} \mathrm{~s} / \mathrm{cm}^{3}$ the gain at $f_{s}=16 \mathrm{GHz}$ varies between $2.6 \mathrm{~dB}$ and $1.3 \mathrm{~dB}$ for $-\pi / 2 \leqslant \phi \leqslant \pi / 2$, whereas the găin variation at $f=32 \mathrm{GHz}$ is between $1.4 \mathrm{~dB}$ and $1.0 \mathrm{~dB}$. At $f_{S}=64 \mathrm{GHz}$ the gain is independent of $\phi_{s}$ and equal to $1.0 \mathrm{~dB}$.

Discussion. The results reported in the preceeding section have demonstrated that theoretically an LSA oscillator or an externally pumped sample of n-type gallium arsenide may be used as an amplifier of small signals at frequencies well above the oscillation frequency. This amplification property arises from the possibility of a net spatial growth of an electromagnetic wave which travels through the oscillating sample.

The results demonstrate, however, that, under the loading conditions considered so far, only moderate gains are obtained. Higher gains may be obtained by choosing more optimal parameters, but the obtainable gain with a single pumped sample used as a transmission amplifier will be rather limited, due to the basic limitations on carrier concentration and sample length (perpendicular to the bias field) relevant to the LSA node.

Therefore it is suggested that a practical amplifier based on the timevarying small-signal conductivity exhibited by an LSA oscillator should consists of a number of properly phased LSA oscillators in series, or be based on multiple reflections in the pumped sample when placed in a cavity of proper dimensions. These possibilities will be further investigated.

By loading the sample with a resonant circuit tuned to one of the sideband frequencies, a converter is obtained. The conversion properties of the ISA oscillator will be further investigated as well.

The proposed amplifier is not subject to transit-time limitations, so it may be possible to design practical amplifiers for use at high millimetre-wave frequencies. The maximum bandwiath is equal to the LSA oscillation frequency.

In the present theory space-charge effects have been neglected. It nay be a requirement for experimental verification that high quality gallium arsenide with a flat doping profile is available.

Acknowlergement. Part of this work was done while the author was at the Bell Telephone Laboratories, Murray Ilill, IJ.J. The author would like to thank J.A. Copeland, Bell Telephone Laboratories, for his initial inspiration and guidance.

References.

\begin{tabular}{|c|c|}
\hline $\mid \begin{array}{l}1 \\
2 \\
3 \\
4 \\
5\end{array}$ & 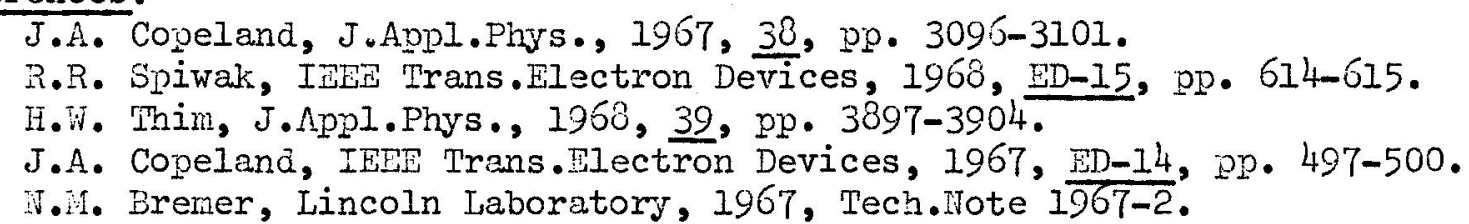 \\
\hline
\end{tabular}




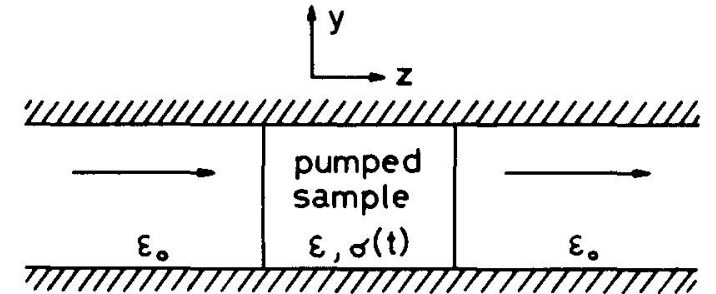

FiE.la. Schematical illustration of the assumed geometry.

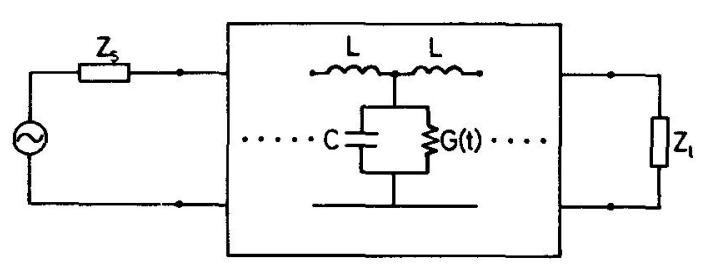

Fif.lb. The transmission-line model.

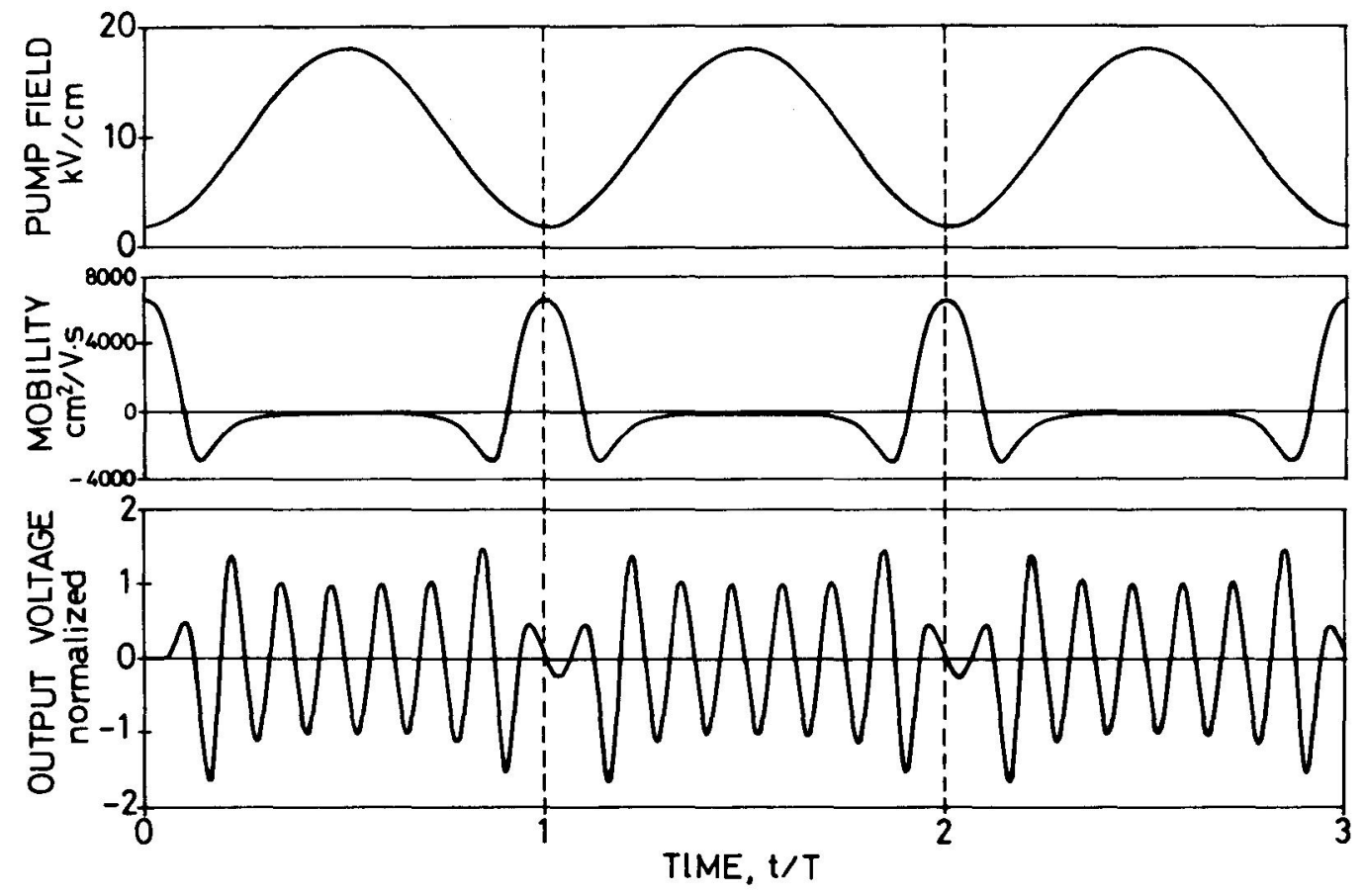

Fig.2. Pump field (upper frame), mobility (middle frame) and normalized output voltage (lower frame) versus time for the

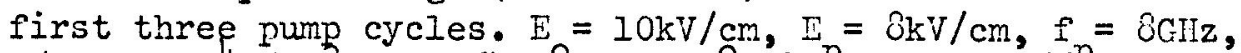

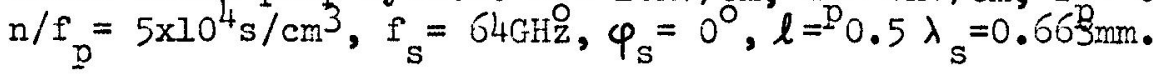

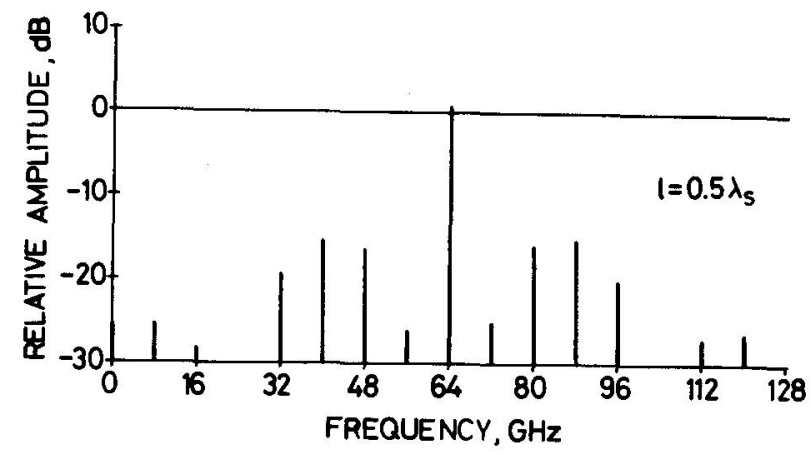

Fig.3. Frequency spectrum corresponding to the output waveform shown in Fig.2.

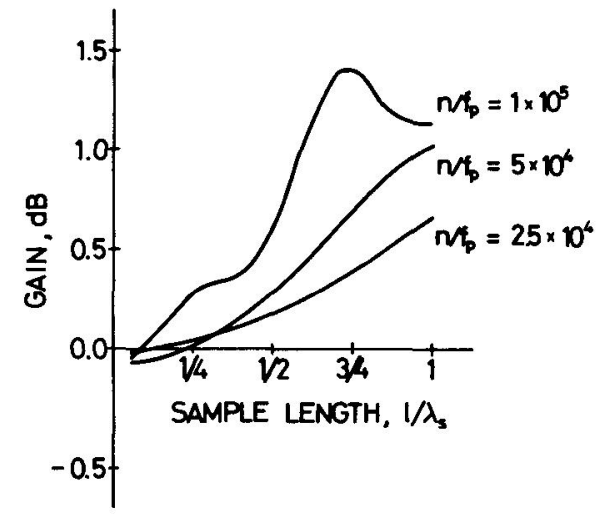

Fig.4. Gain at the signal frequency versus sample lenEth. 